\title{
Caracterização de Opressão de Gênero em Redes Sociais a partir de Violações dos Princípios de Afetibilidade: Um estudo de caso no Facebook
}

\author{
Rafael S. M. Ferreira ${ }^{1}$, Glívia A. R. Barbosa ${ }^{1}$, Carolina Andrade ${ }^{1}$, Ismael S. Silva ${ }^{1}$, \\ Flávio R. S. Coutinho ${ }^{1}$ \\ ${ }^{1}$ Centro Federal de Educação Tecnológica de Minas Gerais (CEFET-MG). Av. \\ Amazonas, 7675 - Nova Gameleira - Belo Horizonte, MG - Brasil. \\ r.salesmf@gmail.com, gliviabarbosaldecom.cefetmg.br, \\ profcarolinarientelgmail.com, ismaelsantanaldecom.cefet.br, \\ coutinho@decom. cefetmg.br
}

\begin{abstract}
Resumo. Este trabalho buscou investigar e caracterizar, por meio de um estudo de caso no Facebook, a aplicabilidade dos princípios de afetibilidade para caracterizar opressão de gênero em redes sociais online. Os resultados demonstraram que o grau de afetibilidade do Facebook reflete em possíveis casos de opressão para pessoas Lésbicas, Gays, Bissexuais e Trans (LGBT). Logo, uma avaliação guiada pelos principios de afetibilidade pode auxiliar na caracterização de situações potencialmente opressoras para esse grupo de usuários.
\end{abstract}

\section{Introdução}

Com o intuito de manter os usuários engajados na utilização continua de softwares sociais, projetistas e pesquisadores (e.g., Barbosa e outros (2013) e Tomagnini e outros (2016)) têm investigado a aplicabilidade da adoção de estratégias de qualidade de uso (e.g., colaboração e sociabilidade) nos modelos de interface e interação desse tipo de sistema. Nessa direção, uma linha de investigação que começa a ser explorada refere-se à incorporação e avaliação de afetibilidade em sistemas, com a finalidade de promover aspectos afetivos a partir da interação [Hayashi et al. 2013][Hayashi et al. 2015].

Porém, apesar dos esforços mencionados, alguns aspectos que caracterizam as necessidades e preferencias de determinados grupos de usuários, como a identidade de gênero e orientação sexual, nem sempre são suficientemente contemplados nos modelos de interface e interação dos sistemas [Pereira e Baranauskas, 2015].

A negligência desses aspectos traz impactos negativos na experiência dos usuários (i.e., comprometem a afetibilidade). Essa afirmação é justificada pelo trabalho realizado por Pereira e Baranauskas (2015), que demonstrou como decisões de design dos softwares sociais têm influenciado na reprodução de opressões baseadas na sexualidade dos indivíduos. Esse trabalho traz à tona a discussão sobre as consequências negativas que a opressão de gênero pode gerar (e.g., baixa afetibilidade para os usuários que se sentem oprimidos) durante a interação mediada por esse tipo de sistema [Hayashi et al. 2013][Pereira e Baranauskas, 2015][Hayashi et al. 2015].

Um grupo suscetível à opressão de gênero é o público formado por pessoas Lésbicas, Gays, Bissexuais e Trans (LGBT), por não se enquadrar nas definições da sociedade em relação à orientação sexual e identidade de gênero [Butler,1999][Pereira e Baranauskas, 2015]. Para exemplificar uma ocorrência de opressão de gênero por meio 
de interfaces, Kannabiran e Petersen (2010) demonstraram que, ao limitar o cadastro de perfil as opções feminino e masculino, o Facebook oprimia os usuários que não se identificavam com essas duas opções de gênero, comprometendo a afetibilidade desse sistema para o público oprimido.

Motivados pelo desafio de identificar e evitar casos de opressão de gênero no modelo de interface e interação dos softwares sociais e considerando a hipótese de que a afetibilidade de um sistema pode refletir sobre a opressão, este trabalho tem como objetivo caracterizar a aplicabilidade dos princípios de afetibilidade para identificar opressão de gênero em redes sociais online. Para isso, foi realizado um estudo de caso no Facebook, considerando usuários LGBTs. O Facebook foi analisado na perspectiva de especialistas em Interação Humano Computado (IHC) e usuários de modo a investigar se o grau de afetibilidade dessa rede social online reflete em possíveis casos de opressão para o público LGBT. O Facebook foi escolhido para o estudo de caso por ser a rede social online mais utilizada no mundo, inclusive no Brasil [Duggan et al. 2014][Duggan e Page, 2015].

Em termos de resultados, além de caracterizar o grau de afetibilidade do Facebook, relacionando-o com a opressão de gênero para o público LGBT, este trabalho discute a aplicabilidade dos princípios de afetibilidade para identificar e evitar opressão no modelo de interface e interação de redes sociais. Isso é relevante uma vez que, segundo Pereira e Baranauskas (2015), existe a demanda por trabalhos que abordem formas de projetar e/ou avaliar sistemas de modo a identificar e evitar opressão, independente do grupo de usuários. Visando essa demanda, o trabalho aqui proposto mostra como os princípios de afetibilidade podem ser úteis nesse contexto.

Dessa forma, esse trabalho contribui para que os projetistas de redes sociais online possam refletir sobre a importância de se endereçar os princípios de afetibilidade em suas soluções tecnológicas, evitando consequências negativas, como a opressão durante a interação. Contribui também para que a afetibilidade se consolide como uma importante qualidade de uso de sistemas e para a consolidação do MIS como um método para identificar estratégias de qualidade de uso. A metodologia proposta pode ser explorada por outros pesquisadores para avaliar tanto afetibilidade quanto opressão em interfaces, já que é crescente a demanda por esse tipo de avaliação [Hayashi et al. 2013][Pereira e Baranauskas, 2015][Hayashi et al. 2015].

\section{Trabalhos Relacionados}

Na literatura, existem diferentes trabalhos que abordam tanto a afetibilidade no contexto de interface e interação em sistemas, quanto a opressão de gênero no mesmo contexto. A afetibilidade como qualidade de uso foi apresentada por Hayashi e outros (2013), que propuseram os Princípios de Afetibilidade como diretrizes para auxiliar projetistas no design e redesign de sistemas voltados para a prática educacional, de forma a incorporar conceitos de afeto e emoção nesse processo.

Fora do âmbito educacional, o trabalho de Hayashi e outros (2015) demonstrou a aplicabilidade dos Princípios de Afetibilidade na construção de aplicativos móveis, a partir do design participativo. Foram desenvolvidos protótipos de sistemas que demonstraram o entendimento dos participantes em relação ao conceito de afeto, além da aplicação dos princípios na elaboração de interfaces. 
Em relação à opressão em interfaces, o estudo de caso realizado por Kannabiran e Peterson (2010) demonstrou como o Facebook pode exercer uma força negativa sobre usuários LGBTs, ao questioná-los sobre seu gênero, mas limitar suas opções de resposta, excluindo qualquer um que não se identifique com as alternativas apresentadas. Posteriormente, Pereira e Baranauskas (2015) conduziram um estudo exploratório para investigar como as interfaces de sistemas digitais, inclusive o Facebook, reproduzem opressão baseada em identidade de gênero e orientação sexual.

Uma vez que a afetibilidade, no contexto de interação, está relacionada aos sentimentos e emoções que podem ser estimulados durante a utilização de sistemas interativos, e essas reações podem ser positivas (e.g., sentimento de alegria) ou negativas (e.g., sentimento de opressão) [Boehner et al. 2007][Hayashi et al. 2013][Pereira e Baranauskas, 2015][Hayashi et al. 2015], o presente trabalho se difere dos demais porque busca investigar a aplicabilidade dos Princípios de Afetibilidade para identificar ocorrências de opressão de gênero para usuários LGBTs em redes sociais online.

\section{Metodologia}

Considerando o objetivo deste trabalho, as seguintes questões de pesquisa foram investigadas: "O grau de afetibilidade do Facebook reflete em possiveis casos de opressão para usuários LGBTs?" e "É possivel utilizar os princípios de afetibilidade para avaliar a opressão?”. A metodologia adotada para responder essas questões consistiu em uma abordagem dividida em 2 fases, subdivididas em etapas.

A primeira fase buscou caracterizar a afetibilidade e opressão de gênero no contexto de IHC para usuários LGBTs. Inicialmente foi conduzida uma revisão bibliográfica para (1) identificar os princípios de afetibilidade para sistemas interativos e (2) caracterizar as decisões no modelo de interface e interação de sistemas que podem refletir em opressão para usuários LGBTs.

Finalmente, foi realizado um mapeamento para demonstrar como a violação dos princípios de afetibilidade pode refletir nas situações potencialmente opressoras identificadas nos modelos de interface e interação dos sistemas. Esse mapeamento foi conduzido por dois especialistas em IHC, com mais de cinco anos de experiência na área, e um especialista em Psicologia, que atua diretamente no tratamento de pessoas LGBTs oprimidas.

A segunda fase buscou caracterizar, sob a perspectiva de especialistas e de usuários, se o grau de afetibilidade do Facebook reflete em possíveis casos de opressão para usuários LGBTs. Para isso, inicialmente foi conduzida uma inspeção na interface do Facebook, utilizando o Método de Inspeção Semiótica (MIS) [de Souza et al. 2006], para identificar por meio da metamensagem do designer e das potenciais rupturas de comunicação: (1) como o Facebook endereça os princípios de afetibilidade em seu modelo de interação e interface e (2) os impactos do grau de afetibilidade dessa rede social na opressão de gênero para usuários LGBTs.

O MIS foi utilizado nessa etapa porque trabalhos como os realizados por Reis e Prates (2011), Barbosa e outros (2013) e Tomagnini e outros (2016), demonstraram a aplicabilidade desse método para identificar as estratégias de design comunicadas na interface que visam potencializar determinadas qualidades de uso (e.g., gamificação, sociabilidade e privacidade). A avaliação utilizando esse método foi conduzida por dois 
especialistas em IHC, sendo que um deles tem mais de oito anos de experiência na aplicação do MIS no contexto de avaliação de sistemas colaborativos.

$\mathrm{Na}$ sequencia, foi aplicado um questionário online para caracterizar a afetibilidade e opressão no Facebook, sob a perspectiva dos usuários LGBTs. Finalmente, foi realizada a triangulação dos resultados para: (1) caracterizar a maneira como a afetibilidade no Facebook reflete na opressão de gênero e (2) discutir a aplicabilidade dos princípios de afetibilidade para caracterizar opressão de gênero em redes sociais online.

\section{Afetibilidade e Opressão de Gênero no Contexto de Interação}

Por meio de uma revisão bibliográfica esse trabalho buscou caracterizar a afetibilidade e opressão de gênero no contexto de IHC para usuários LGBTs. As buscas foram realizadas no Google Scholar ${ }^{1}$ e nos principais repositórios de pesquisas relacionados à área de Computação, IEEE Xplore ${ }^{2}$, ACM Digital Library ${ }^{3}$, Springer $^{4}$ e HCI Bib ${ }^{5}$. A string de pesquisa contemplava os seguintes termos (em português e, respectiva, tradução em inglês): afetibilidade, opressão de gênero, redes sociais online.

Essa revisão foi conduzida por dois especialistas em IHC e um especialista em Psicologia com o objetivo de demonstrar como a violação dos princípios de afetibilidade pode refletir nas situações potencialmente opressoras identificadas nos modelos de interface e interação dos sistemas. A seguir, os principais resultados são apresentados.

\subsection{Afetibilidade em Sistemas Interativos}

A partir dessa pesquisa foi possível constatar que, conforme apontado por Boehner e outros (2007), o afeto é um conceito que abrange condições como emoções, sentimentos, preferências e humores, e está relacionado a valores atribuídos a algo ou alguém, de forma positiva ou negativa. Portanto, a abordagem ao afeto deve ser realizada considerando a singularidade de cada indivíduo.

No contexto de IHC, a afetibilidade (ou grau de afeto) refere-se às respostas afetivas que um usuário pode experimentar ao interagir com um sistema [Hayashi et al. 2015]. Com o intuito de maximizar a afetibilidade durante o uso de sistemas interativos, foram propostos os Princípios de Design para Afetibilidade [Hayashi et al. 2015], que podem ser utilizados como referência tanto para o projeto, quanto para avaliação de sistemas. A Tabela 1 lista os Princípios de Afetibilidade para IHC apresentados por Hayashi e outros (2015).

Seguir os princípios de afetibilidade no design e/ou avaliação pode potencializar o afeto entre o usuário e o sistema durante a interação. Isso porque, embora não seja possível garantir que o afeto seja influenciado exclusivamente por essas diretrizes, adotá-las na interface visa maximizar a experiência satisfatória do usuário durante a interação. Caso contrário, não considerar a afetibilidade durante a concepção de um

\footnotetext{
${ }^{1}$ Google Scholar - https://scholar.google.com.br/

${ }^{2}$ IEEE Xplore - http://ieeexplore.ieee.org/Xplore/home.jsp

${ }^{3}$ ACM Digital Library - http://dl.acm.org/

${ }^{4}$ Springer - http://www.springer.com/br/

${ }^{5} \mathrm{HCI} \mathrm{Bib} \mathrm{-} \mathrm{http://hcibib.org/}$
} 
sistema, pode refletir em sentimentos negativos a partir da interação, como por exemplo, a opressão [Pereira e Baranauskas, 2015][Hayashi et al. 2015].

Tabela 1. Princípios de Afetibilidade para Sistemas Interativos

\begin{tabular}{|c|c|c|c|}
\hline Cód. & Nome do Princípio & Descrição & Exemplo em Interfaces \\
\hline PAf1 & $\begin{array}{l}\text { Permitir a } \\
\text { comunicação de } \\
\text { estados afetivos } \\
\end{array}$ & $\begin{array}{l}\text { O afeto deve ser expressado e } \\
\text { interpretado de forma livre por cada } \\
\text { usuário. }\end{array}$ & $\begin{array}{l}\text { A personalização de fotos no Snapchat, } \\
\text { por meio de desenhos, stickers e filtros. }\end{array}$ \\
\hline PAf2 & $\begin{array}{l}\text { Considerar o contexto } \\
\text { social do usuário } \\
\text { (cultura e valores) }\end{array}$ & $\begin{array}{l}\text { Deve-se considerar a cultura e valores } \\
\text { humanos importantes para o usuário } \\
\text { alvo no design. }\end{array}$ & $\begin{array}{l}\text { Os doodles que o Google mostra em sua } \\
\text { página inicial representando datas } \\
\text { comemorativas. }\end{array}$ \\
\hline PAf3 & Possibilitar tailoring & $\begin{array}{l}\text { O usuário tem permissão para inserir } \\
\text { seu próprio conteúdo e personalizar } \\
\text { elementos do sistema. }\end{array}$ & $\begin{array}{l}\text { A personalização de perfil de usuário e } \\
\text { preferências em redes sociais. }\end{array}$ \\
\hline PAf4 & $\begin{array}{l}\text { Promover a construção } \\
\text { colaborativa }\end{array}$ & $\begin{array}{l}\text { O usuário tem permissão contribuir uns } \\
\text { com os outros durante a interação. }\end{array}$ & $\begin{array}{l}\text { Waze, que permite que o usuário insira } \\
\text { informações sobre o estado do trânsito, o } \\
\text { que será disseminado para outros. }\end{array}$ \\
\hline PAf5 & $\begin{array}{l}\text { Promover awareness } \\
\text { social }\end{array}$ & $\begin{array}{l}\text { O usuário consegue identificar a } \\
\text { presença ou estado dos outros usuários. }\end{array}$ & $\begin{array}{l}\text { Jogos online, como Candy Crush, que } \\
\text { mostram para o usuário a posição de cada } \\
\text { amigo que também joga. }\end{array}$ \\
\hline PAf6 & $\begin{array}{l}\text { Explorar a } \\
\text { "contaminação" via } \\
\text { mídia }\end{array}$ & $\begin{array}{l}\text { Explorar diferentes mídias como sons, } \\
\text { imagens e cores. }\end{array}$ & $\begin{array}{l}\text { Jogos online, que exploram imagens e } \\
\text { diferentes resultados sonoros para } \\
\text { diferentes ações. }\end{array}$ \\
\hline
\end{tabular}

\subsection{Opressão de Gênero para Usuários LGBTs em Sistemas Interativos}

A construção de um sistema empregando o conceito de afetibilidade deve considerar o contexto no qual o usuário está inserido, além de aspectos que envolvam as particularidades de cada indivíduo [Hayashi et al. 2013][Hayashi et al. 2015]. Fatores da sexualidade humana (e.g., a identidade de gênero), porém, costumam ser negligenciados, levando a chamada opressão de gênero e a uma baixa afetibilidade para o grupo oprimido [Pereira e Baranauskas, 2015][Hayashi et al. 2015].

A identidade de gênero se relaciona com a maneira como a pessoa se enxerga e é comumente associada à genitália do indivíduo, caracterizando-o como homem ou mulher. Porém, essas duas classificações são pontos extremos entre os quais a identidade de gênero de uma pessoa pode se encontrar. Já a maneira como um indivíduo expressa sua identidade de gênero é chamada de expressão de gênero, sendo caracterizada, por exemplo, pela forma como o indivíduo se veste, age e se comporta. Assim como a identidade de gênero, a expressão de gênero consiste em um espectro dentro do qual um indivíduo tem infinitas maneiras de se encontrar [Killermann, 2011].

Essas duas características são comumente associadas ao sexo biológico do indivíduo, observado não só pela genitália, mas também por características como hormônios e cromossomos. Porém, além dos sexos masculino e feminino, existem pessoas intersex, nascidas com características biológicas de ambos os sexos. Algumas pessoas identificam seu gênero com o sexo atribuído, essas são conhecidas como cisgêneras. Por sua vez, as pessoas transgêneras são aquelas que não se identificam com o sexo designado [Killermann, 2011][Butler,1999][Pereira e Baranauskas, 2015].

A orientação sexual está associada ao objeto de desejo afetivo ou sexual. Indivíduos heterossexuais são aqueles que sentem-se atraídos unicamente por pessoas de outro gênero, enquanto homossexuais se atraem exclusivamente pelo mesmo gênero. 
Bissexualidade implica na atração por dois gêneros, enquanto os pansexuais são aqueles atraídos por mais de dois gêneros [Killermann, 2011].

Como argumentado por Butler (1999), a sociedade possui uma regulamentação compulsória de que as pessoas são cisgêneras e heterossexuais. Essa regulamentação é definida como matriz heterossexual, que delimita as características específicas de gêneros, corpos e desejos perpetuados na sociedade. Por exemplo, a matriz heterossexual determina quais ações (e.g., maneiras de se vestir e falar) descrevem um homem ou uma mulher [Butler, 1999]. Desse modo, como as características esperadas pela sociedade para representar determinado indivíduo estão definidas a partir da matriz heterossexual, aqueles que não se identificam com esse tipo de orientação sexual (e.g., pessoas lésbicas, gays, bissexuais e trans (LGBTs)) são excluídos [Butler, 1999].

No contexto de IHC, um exemplo dessa exclusão pode ser verificado quando uma rede social online limita o usuário às opções: feminino ou masculino para a caracterização de seu perfil, desconsiderando outras identidades de gênero (e.g., pessoas trans). Desse modo, para expressar sua identidade, o usuário procura outras formas, como escrevê-la na seção de biografia [Pereira e Baranauskas, 2015].

Esse exemplo demonstra uma situação em que o sistema oprime um usuário LGBT, ao proibi-lo de se expressar por meio do recurso específico para identidade de gênero, contribuindo para uma baixa afetibilidade entre esse usuário e o sistema [Hayashi et al. 2013][Pereira e Baranauskas, 2015][Hayashi et al. 2015]. Essa opressão e baixa afetibilidade se tornam mais evidentes quando Pereira e Baranauskas (2015) relatam que pessoas cisgêneras e heterossexuais têm uma menor percepção de casos de opressões nas interfaces, quando comparadas com os usuários LGBTs que, além de perceberem mais essas ocorrências, consideram o grau de opressão um fator importante para a aceitação de um sistema [Pereira e Baranauskas, 2015].

Nesse sentido, Pereira e Baranauskas (2015) conduziram um estudo exploratório para investigar como as interfaces de sistemas digitais reproduzem opressão de gênero e qual o efeito dessa opressão na decisão de uso e no conforto de quem utiliza tais sistemas. A Tabela 2 sumariza as ocorrências de opressão de gênero, identificadas por Pereira e Baranauskas (2015), que podem ser percebidos no modelo de interface e interação de sistemas.

Tabela 2. Ocorrências de Opressão na Interface de Sistemas Interativos

\begin{tabular}{|c|c|c|c|}
\hline & Código & Nome & Descrição e exemplo em interfaces \\
\hline \multirow{3}{*}{$\begin{array}{l}\text { Opressões } \\
\text { na interface }\end{array}$} & OcOp 1 & $\begin{array}{l}\text { Formulários } \\
\text { Impróprios } \\
\text { ausentes }\end{array}$ & $\begin{array}{l}\text { Formulários com informações erradas, como perguntar o sexo do } \\
\text { usuário ao invés de seu gênero ou opções restritas, como perguntar se } \\
\text { o gênero do usuário é masculino ou feminino. }\end{array}$ \\
\hline & OcOp 2 & $\begin{array}{lr}\text { Elementos } & \text { gráficos } \\
\text { impróprios } & \text { na } \\
\text { interface } & \end{array}$ & $\begin{array}{l}\text { Cores, imagens e qualquer outro elemento gráfico que contenha } \\
\text { informações impróprias, como cores culturalmente associadas a } \\
\text { gênero, como rosa sendo feminino e azul, masculino. }\end{array}$ \\
\hline & OcOp 3 & $\begin{array}{l}\text { Texto impróprio ou } \\
\text { ofensivo na interface }\end{array}$ & $\begin{array}{l}\text { Texto que contenha elementos que possam ser ofensivos para } \\
\text { usuários LGBTs. }\end{array}$ \\
\hline \multirow{2}{*}{$\begin{array}{l}\text { Opressões } \\
\text { na } \\
\text { interação }\end{array}$} & OcOp 4 & $\begin{array}{l}\text { Texto impróprio de } \\
\text { usuário }\end{array}$ & $\begin{array}{l}\text { Textos ofensivos contra pessoas LGBTs que tenham sido publicados } \\
\text { ou propagados por outros usuários, direcionados ou não a um usuário } \\
\text { específico. }\end{array}$ \\
\hline & OcOp 5 & $\begin{array}{l}\text { Mídias impróprias } \\
\text { propagadas por } \\
\text { usuário }\end{array}$ & $\begin{array}{l}\text { Mídias como imagens ou vídeos que contenham discurso ofensivo } \\
\text { contra pessoas LGBTs e que sejam publicadas ou compartilhadas por } \\
\text { usuários. }\end{array}$ \\
\hline
\end{tabular}




\begin{tabular}{|l|l|l|l|}
\hline OcOp 6 & $\begin{array}{l}\text { Ações de usuários } \\
\text { motivadas } \\
\text { preconceito }\end{array}$ & $\begin{array}{l}\text { Ações realizadas por usuários com ou sem permissão para } \\
\text { administrar conteúdo, que sejam ofensivas ou preconceituosas, como } \\
\text { denúncia do perfil porque o usuário é LGBT. }\end{array}$ \\
\hline
\end{tabular}

\subsection{Reflexo da Afetibilidade na Opressão de Gênero para Usuários LGBTs}

Conforme mencionado anteriormente, as ocorrências de opressão afetam na decisão de uso e no conforto (e.g., afetibilidade) de quem utiliza os sistemas interativos [Pereira e Baranauskas, 2015]. Nesse sentido, a partir dos resultados apresentados por Pereira e Baranauskas (2015) e Hayashi e outros (2015), este trabalho buscou mapear como as situações potencialmente opressoras, listadas na Tabela 2 , podem estar relacionadas a violações dos princípios de afetibilidade, descritos na Tabela 1.

Esse mapeamento foi conduzido por dois especialistas em IHC e um especialista em Psicologia que atua diretamente no tratamento de pessoas LGBTs oprimidas. Os resultados dessa análise são apresentados na Tabela 3, que explicita os códigos dos princípios de afetibilidade (PAf) violados, a partir de cada ocorrência de opressão (OcOp), e apresenta uma justificativa de porque a referida situação opressora pode refletir na violação do respectivo princípio de afetibilidade.

Tabela 3. Relação entre as Ocorrências de Opressão para Usuários LGBTs e a Violação dos Princípios de Afetibilidade

\begin{tabular}{|c|c|c|c|}
\hline $\begin{array}{l}\text { Cód. Oc. de } \\
\text { Opressão }\end{array}$ & $\begin{array}{l}\text { Descrição da Oc. } \\
\text { Opressora }\end{array}$ & $\begin{array}{l}\text { Cód. Princ. } \\
\text { Afetibilidade } \\
\text { Violado } \\
\end{array}$ & $\begin{array}{c}\text { Justificativa da relação entre a situação opressora e a violação } \\
\text { da afetibilidade }\end{array}$ \\
\hline \multirow{4}{*}{ OcOp 1} & \multirow{4}{*}{$\begin{array}{l}\text { Formulários } \\
\text { Impróprios ou } \\
\text { ausentes }\end{array}$} & PAf1 & $\begin{array}{l}\text { Um formulário impróprio impede o usuário de se expressar } \\
\text { livremente ao não incluir opções com as quais este se identifica. }\end{array}$ \\
\hline & & PAf2 & $\begin{array}{l}\text { Formulários que não contenham opções com as quais o usuário } \\
\text { LGBT se identifica foram criados sem considerar esse grupo de } \\
\text { pessoas. }\end{array}$ \\
\hline & & PAf3 & $\begin{array}{l}\text { O usuário não consegue personalizar o perfil para refletir sua } \\
\text { identidade por não lhe terem sido oferecidas opções com as quais } \\
\text { se identifique. }\end{array}$ \\
\hline & & PAf5 & $\begin{array}{l}\text { Uma das consequências de um usuário não se expressar como } \\
\text { deseja é que dificulta o awareness social, ao impedir que os } \\
\text { usuários se expressem como desejam para os outros. }\end{array}$ \\
\hline \multirow{3}{*}{ OcOp 2} & \multirow{3}{*}{$\begin{array}{l}\text { Elementos gráficos } \\
\text { impróprios na } \\
\text { interface }\end{array}$} & PAf1 & $\begin{array}{l}\text { Um elemento gráfico potencialmente opressor pode influenciar } \\
\text { um sentimento negativo. }\end{array}$ \\
\hline & & PAf2 & $\begin{array}{l}\text { Elementos gráficos potencialmente opressores para pessoas } \\
\text { LGBT foram criados sem considerar esse grupo de usuários. }\end{array}$ \\
\hline & & PAf6 & $\begin{array}{l}\text { A contaminação por mídia, quando realizada a partir de elementos } \\
\text { potencialmente opressores, pode induzir a um sentimento } \\
\text { negativo. }\end{array}$ \\
\hline \multirow{2}{*}{ OcOp 3} & \multirow{2}{*}{$\begin{array}{l}\text { Texto impróprio ou } \\
\text { ofensivo na } \\
\text { interface }\end{array}$} & PAf1 & $\begin{array}{l}\text { Um texto potencialmente opressor pode influenciar um } \\
\text { sentimento negativo. }\end{array}$ \\
\hline & & PAf2 & $\begin{array}{l}\text { Textos potencialmente opressores para pessoas LGBT foram } \\
\text { criados sem considerar esse grupo de usuários. }\end{array}$ \\
\hline \multirow{3}{*}{ OcOp 4} & \multirow{3}{*}{$\begin{array}{l}\text { Texto impróprio de } \\
\text { usuário }\end{array}$} & PAf1 & $\begin{array}{l}\text { Um texto potencialmente opressor pode influenciar um } \\
\text { sentimento negativo. }\end{array}$ \\
\hline & & PAf4 & $\begin{array}{l}\text { A construção colaborativa pode ter como consequência a } \\
\text { influência de sentimento negativo quando a contribuição de um } \\
\text { usuário é um texto potencialmente opressor. }\end{array}$ \\
\hline & & PAf5 & $\begin{array}{l}\text { O awareness social pode ter como consequência a influência de } \\
\text { sentimentos negativos quando há usuários publicando textos }\end{array}$ \\
\hline
\end{tabular}




\begin{tabular}{|c|c|c|c|}
\hline & & & potencialmente opressores. \\
\hline \multirow{3}{*}{ OcOp 5} & \multirow{3}{*}{$\begin{array}{l}\text { Mídias impróprias } \\
\text { propagadas por } \\
\text { usuário }\end{array}$} & PAf1 & $\begin{array}{l}\text { Mídias potencialmente opressoras podem influenciar um } \\
\text { sentimento negativo. }\end{array}$ \\
\hline & & PAf4 & $\begin{array}{l}\text { A construção colaborativa pode ter como consequência a } \\
\text { influência de sentimento negativo quando a contribuição de um } \\
\text { usuário é uma mídia potencialmente opressora. }\end{array}$ \\
\hline & & PAf5 & $\begin{array}{l}\text { O awareness social pode ter como consequência a influência de } \\
\text { sentimentos negativos quando há usuários publicando mídias } \\
\text { potencialmente opressoras. }\end{array}$ \\
\hline \multirow{3}{*}{ OcOp 6} & \multirow{3}{*}{$\begin{array}{l}\text { Ações de usuários } \\
\text { motivadas por } \\
\text { preconceito }\end{array}$} & PAf1 & $\begin{array}{l}\text { Uma ação potencialmente motivada por preconceito pode } \\
\text { influenciar um sentimento negativo em usuários LGBT. }\end{array}$ \\
\hline & & PAf4 & $\begin{array}{l}\text { A contribuição de uma ação potencialmente motivada por } \\
\text { preconceito pode gerar um sentimento negativo em usuários } \\
\text { LGBT. }\end{array}$ \\
\hline & & PAf5 & $\begin{array}{l}\text { O awareness social pode ter como consequência a influência de } \\
\text { sentimentos negativos quando ocorrem ações potencialmente } \\
\text { opressoras por parte de usuários. }\end{array}$ \\
\hline
\end{tabular}

Por meio da Tabela 3 é possível observar que ocorrências de opressão de gênero podem estar associadas à violação de um ou mais Princípios de Afetibilidade no contexto de usuários LGBTs. Em outras palavras, a violação desses princípios pode induzir o sentimento negativo de opressão.

Considerando o exposto até o momento, a próxima etapa do trabalho consistiu em um estudo de caso no Facebook para discutir se a partir de uma avaliação de afetibilidade é possível caracterizar potenciais ocorrências de opressão de gênero em redes sociais online.

\section{Afetibilidade e Opressão no Facebook sob a perspectiva de Especialistas}

Nesta seção é apresentada a análise da interface do Facebook, utilizando o MIS, que buscou caracterizar a proposta do projetista para potencializar a afetibilidade nessa rede social e, além disso, indicar as potenciais rupturas nessa proposta que refletiam em casos de opressão para usuários LGBTs.

A avaliação foi realizada no período de 20 dias do mês de Agosto de 2016 e conduzida por dois especialistas em IHC, sendo que um deles tem mais de oito anos de experiência na aplicação do método no contexto de avaliação de sistemas colaborativos. Além disso, houve o apoio de um psicólogo, que auxiliou nas fases de: (1) associar estratégias de design do Facebook e princípios de afetibilidade e (2) relacionar as rupturas de afetibilidade com possíveis casos de opressão.

O escopo da avaliação contemplou os seguintes cenários de uso do Facebook: (1) criação de perfil, (2) personalização de perfil, (3) configurações de privacidade, (4) compartilhamento de conteúdo, (5) interação com conteúdo publicado e (6) interação entre usuários. Esses cenários foram escolhidos por consistirem no fluxo básico do sistema, englobando as principais funcionalidades oferecidas pelo Facebook.

\subsection{Proposta de Afetibilidade do Facebook}

A partir da inspeção, em termos de afetibilidade, foi possível verificar que no Facebook cada usuário possui um perfil com suas informações pessoais e cria uma rede de conexões, com a qual pode entrar em contato por meio da comunicação direta via chat e compartilhamento de conteúdo (e.g., textos, imagens ou vídeos). 
O perfil é criado de modo a explicitar o nome, a data de nascimento e o gênero, que no momento do cadastro está limitado a feminino ou masculino. A partir desse gênero, o sistema insere uma imagem com uma silhueta masculina ou feminina para representar o usuário até que seja inserida uma nova imagem. Posteriormente, o perfil pode ser editado para alteração e/ou inclusão de diversas outras informações (e.g., educação, trabalho e gênero personalizado). Além disso, com exceção do nome, a foto e o gênero, o proprietário da conta pode controlar quem tem acesso (i.e., todos, somente amigos ou ninguém) aos dados do seu perfil.

Após o estabelecimento de uma conexão, que só acontece quando os dois usuários estão de acordo, a interação e a reciprocidade no Facebook são incentivadas a partir do compartilhamento de conteúdo (e.g., textos, imagens, vídeos ou a publicação de outro usuário ou página). O proprietário da publicação pode personalizar a visibilidade do conteúdo e caso não haja restrições, aqueles que têm permissão podem interagir com a postagem por meio de comentários, novos compartilhamentos e/ou reações que podem ser manifestadas pelas expressões: "Curtir", "Amei", "Haha", "Uau", "Triste" ou "Grr". Além disso, o Facebook disponibiliza outros recursos para interação como grupos, eventos e comunicação instantânea.

Visando a segurança o projetista oferece aos usuários a possibilidade de ocultar uma publicação própria ou de terceiros, bem como uma opção para denunciar publicações e perfis, quando esses conteúdos não correspondem ao propósito da rede (e.g., incitações a discurso de ódio ou violência). Além disso, o sistema permite que um usuário bloqueie qualquer pessoa que desejar.

\subsection{Estratégias de Afetibilidade adotadas pelo Facebook}

Uma vez identificada a proposta de afetibilidade do Facebook, este trabalho buscou verificar se as decisões comunicadas na interface dessa rede social são compatíveis com os princípios que, de acordo com Hayashi e outros (2015), podem contribui para potencializar o afeto do usuário durante a interação mediada pelo Facebook. A Tabela 4 relaciona as decisões adotadas pelo projetista, identificadas por meio do MIS, com os princípios de afetibilidade disponíveis na literatura (listados na Tabela 1).

Tabela 4. Estratégias de Afetibilidade do Facebook identificadas a partir do MIS

\begin{tabular}{|l|l|l|c|}
\hline \multicolumn{1}{|c|}{$\begin{array}{l}\text { Cod. e Decisões do Projetista do } \\
\text { Facebook }\end{array}$} & $\begin{array}{l}\text { Exemplo (evidência) de aplicação no Facebook } \\
\text { (i.e., signos que evidenciam) }\end{array}$ & $\begin{array}{l}\text { Cód. Princípio de } \\
\text { Afetibilidade relacionado }\end{array}$ \\
\hline D001 & Criar um perfil. & $\begin{array}{l}\text { É possível criar uma nova conta no Facebook e } \\
\text { construir um novo perfil e rede de contatos. }\end{array}$ & PAf3 \\
\hline D002 & Excluir o perfil. & $\begin{array}{l}\text { É possível apagar o perfil no sistema quando não se } \\
\text { deseja mais fazer parte da rede. }\end{array}$ & PAf3 \\
\hline D003 & Personalizar o perfil. & $\begin{array}{l}\text { O sistema permite que o usuário construa seu perfil } \\
\text { incluindo as informações que deseja. Além disso, é } \\
\text { possível customizar a visibilidade de cada } \\
\text { informação adicionada. }\end{array}$ & PAf2 \\
\hline D004 & $\begin{array}{l}\text { Escolher um gênero } \\
\text { personalizado. }\end{array}$ & $\begin{array}{l}\text { personalizado, além de feminino e masculino, } \\
\text { levando em conta que existem outros gêneros além } \\
\text { destes. }\end{array}$ & PAf5 \\
\hline D005 & $\begin{array}{l}\text { Visualizar } \\
\text { informações relevantes } \\
\text { de usuários. }\end{array}$ & $\begin{array}{l}\text { O sistema permite a um usuário saber diversas } \\
\text { informações sobre cada usuário, desde nome e idade } \\
\text { até estado civil e cidade onde mora. }\end{array}$ & \\
\hline
\end{tabular}




\begin{tabular}{|c|c|c|c|}
\hline D006 & $\begin{array}{l}\text { Adicionar amigos } \\
\text { através de sugestão do } \\
\text { Facebook. }\end{array}$ & $\begin{array}{l}\text { O Facebook sugere amigos que o usuário possa } \\
\text { conhecer para que iniciem uma conexão. }\end{array}$ & PAf2 \\
\hline D007 & $\begin{array}{l}\text { Aceitar ou recusar } \\
\text { convite para iniciar } \\
\text { uma conexão. }\end{array}$ & $\begin{array}{l}\text { O sistema só considera a conexão iniciada quando } \\
\text { um usuário aceita o convite de amizade do outro. Do } \\
\text { contrário, é considerado que nunca se adicionaram. }\end{array}$ & PAf3, PAf4 \\
\hline D008 & $\begin{array}{l}\text { Publicar conteúdo } \\
\text { livremente dentro do } \\
\text { propósito da rede. }\end{array}$ & $\begin{array}{l}\text { O usuário pode publicar o conteúdo que desejar no } \\
\text { Facebook dentre texto, imagens, vídeos ou links, } \\
\text { desde que estejam de acordo com as regras do site. }\end{array}$ & PAf1 \\
\hline D009 & $\begin{array}{lr}\text { Controlar } & \text { a } \\
\text { visibilidade } & \text { das } \\
\text { publicações. } & \end{array}$ & $\begin{array}{l}\text { O sistema permite que o usuário escolha quais } \\
\text { conexões podem visualizar suas publicações, entre } \\
\text { as opções: (1) público, (2) somente amigos, (3) } \\
\text { privado e (4) personalizado, podendo escolher } \\
\text { contatos específicos. }\end{array}$ & PAf3 \\
\hline D010 & $\begin{array}{l}\text { Personalizar } r \\
\text { conteúdo que deseja } \\
\text { visualizar. }\end{array}$ & $\begin{array}{l}\text { Deixar que o usuário escolha de quais contatos } \\
\text { prefere visualizar publicações. }\end{array}$ & PAf 3 \\
\hline D011 & Ocultar publicações. & $\begin{array}{l}\text { O sistema permite que o usuário oculte publicações } \\
\text { que não deseja ver. }\end{array}$ & PAf3 \\
\hline D012 & $\begin{array}{l}\text { Livre expressão sobre } \\
\text { algum conteúdo } \\
\text { publicado. }\end{array}$ & $\begin{array}{l}\text { O usuário pode responder qualquer publicação } \\
\text { demonstrando seu sentimento em relação a ela, } \\
\text { através do botão de curtir ou comentário. }\end{array}$ & PAf1 \\
\hline D013 & $\begin{array}{l}\text { Diferentes reações } \\
\text { para responder a uma } \\
\text { publicação. }\end{array}$ & $\begin{array}{l}\text { O sistema permite que o usuário responda a uma } \\
\text { publicação escolhendo uma entre as reações } \\
\text { "Curtir", "Amei", "Haha", "Uau", "Triste" ou "Grr", } \\
\text { cada uma acompanhada por um elemento gráfico } \\
\text { diferente. }\end{array}$ & PAf3, PAf6 \\
\hline D014 & $\begin{array}{l}\text { Utilizar diferentes } \\
\text { recursos para contato } \\
\text { com usuários. }\end{array}$ & $\begin{array}{l}\text { O Facebook oferece uma série de recursos para que } \\
\text { os usuários entrem em contato entre si, como chats } \\
\text { privados, criação de eventos e de grupos. }\end{array}$ & PAf3 \\
\hline D015 & $\begin{array}{l}\text { Denunciar perfis ou } \\
\text { publicações } \\
\text { incompatíveis com o } \\
\text { propósito da rede }\end{array}$ & $\begin{array}{l}\text { O sistema permite que o usuário denuncie outros } \\
\text { usuários e publicações que sejam potencialmente } \\
\text { opressores ou perigosos, possibilitando que a } \\
\text { administração do site tome as providências. }\end{array}$ & PAf4 \\
\hline D016 & $\begin{array}{l}\text { Bloquear usuários } \\
\text { indesejados. }\end{array}$ & $\begin{array}{l}\text { O Facebook permite que um usuário bloqueie outro. } \\
\text { Quando isso ocorre, nenhum desses verá mais } \\
\text { publicações ou o perfil do outro pela rede. }\end{array}$ & PAf3 \\
\hline
\end{tabular}

A Figura 1 evidencia alguns exemplos das decisões do projetista do Facebook para potencializar a afetibilidade do sistema, referenciadas pelo código da coluna " $\mathrm{Cod}$. e Decisões do Projetista do Facebook", na Tabela 4.
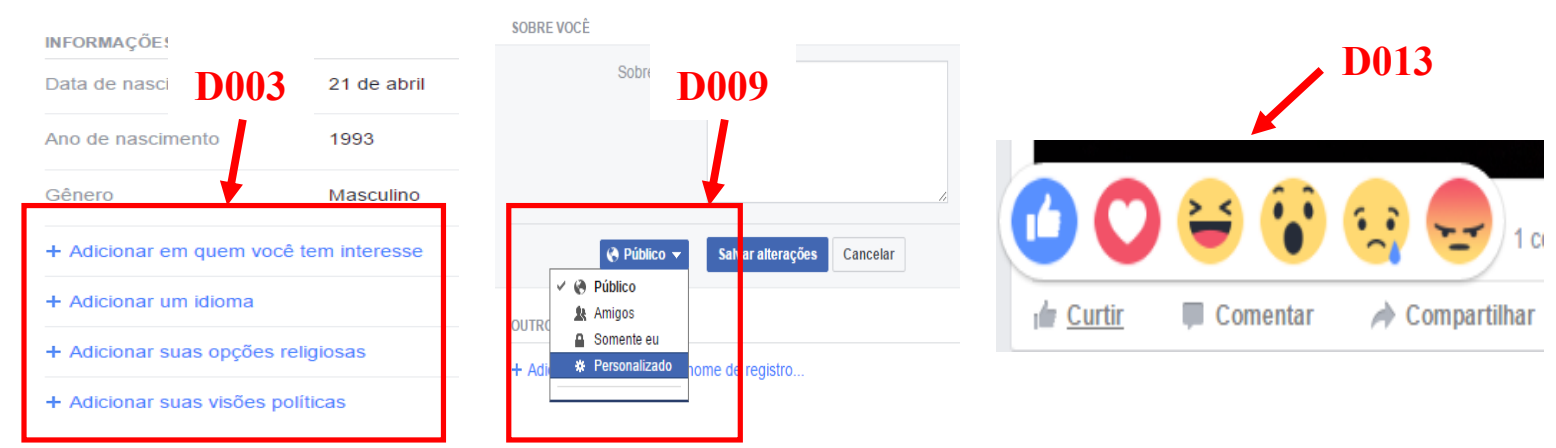

Figura 1. Signos na interface do Facebook que evidenciam as decisões do projetista 


\subsection{Rupturas nas Estratégias de Afetibilidade e Potencial Impacto na Opressão}

A partir da inspeção com o MIS foi possível identificar seis rupturas na interface do Facebook que violaram princípios de afetibilidade. Essas violações foram analisadas na perspectiva de especialistas em IHC e de um profissional de psicologia de modo que fosse possível evidenciar como as rupturas de afetibilidade poderiam refletir em situações opressoras para o público LGBT.

Os resultados dessa análise são exibidos na Tabela 5. Nessa tabela, são apresentados: o código e o nome da ruptura, os princípios de afetibilidade que ela viola (por meio de seus respectivos códigos) e a possível situação opressora que essa violação pode gerar durante a interação de um usuário LGBT. Além disso, a última coluna indica o código de ocorrências de opressão de gênero similares (listadas na Tabela 2), relatadas anteriormente por usuários LGBTs, que ajudam a reforçar o argumento que as violações dos princípios de afetibilidade na interface do Facebook podem refletir em situações opressoras para esse tipo de usuário. A Figura 2 exemplifica essas rupturas.

Tabela 5. Rupturas de Afetibilidade do Facebook e reflexos na Opressão

\begin{tabular}{|c|c|c|c|c|}
\hline \multicolumn{2}{|c|}{ Cod. e Nome da Ruptura } & \multirow{2}{*}{$\begin{array}{l}\begin{array}{l}\text { Cód. dos Princ. } \\
\text { de Afetibilidade } \\
\text { violados }\end{array} \\
\begin{array}{l}\text { PAf1, PAf2, } \\
\text { PAf3 e PAf5 }\end{array}\end{array}$} & \multirow{2}{*}{$\begin{array}{l}\text { Reflexo na opressão de gênero contra } \\
\text { pessoas LGBT } \\
\text { Durante a criação do perfil, o usuário é } \\
\text { obrigado a escolher seu gênero entre } \\
\text { masculino e feminino. Isso pode gerar } \\
\text { opressão de gênero porque, segundo os } \\
\text { dados apresentados por Pereira e } \\
\text { Baranauskas (2015), o usuário pode não se } \\
\text { identificar com nenhuma das opções dadas. }\end{array}$} & \multirow{2}{*}{$\begin{array}{l}\text { Cód. de situações } \\
\text { opressoras similares } \\
\text { já relatadas por } \\
\text { usuários LGBTs } \\
\text { OcOp } 1\end{array}$} \\
\hline R001 & $\begin{array}{l}\text { Gênero restrito a } \\
\text { masculino e } \\
\text { feminino na } \\
\text { criação de perfil. }\end{array}$ & & & \\
\hline R002 & $\begin{array}{lr}\text { Silhueta } & \text { de } \\
\text { imagem } & \\
\text { vinculada } & \text { a } \\
\text { gênero } & \text { pré- } \\
\text { escolhido. } & \end{array}$ & $\begin{array}{l}\text { PAf1, PAf2 e } \\
\text { PAf6 }\end{array}$ & $\begin{array}{l}\text { Após a escolha do gênero pelo usuário } \\
\text { durante a criação da conta, o sistema coloca } \\
\text { em seu perfil uma imagem genérica } \\
\text { contendo uma silhueta de cabelo longo para } \\
\text { o gênero feminino e de cabelo curto para o } \\
\text { gênero masculino. Segundo os dados } \\
\text { apresentados por Pereira e Baranauskas } \\
\text { (2015), isso pode ser opressor porque o } \\
\text { usuário pode não se identificar com a } \\
\text { imagem designada. }\end{array}$ & OcOp 2 \\
\hline R003 & $\begin{array}{l}\text { Pronomes } \\
\text { tratamento } \\
\text { limitados. }\end{array}$ & $\begin{array}{l}\text { PAf1, PAf2, } \\
\text { PAf3 e PAf5. }\end{array}$ & $\begin{array}{l}\text { O Facebook permite que o usuário } \\
\text { personalize as informações do perfil, } \\
\text { inclusive o gênero. Ao editar o gênero o } \\
\text { sistema oferece ao usuário a opção de } \\
\text { indicar o pronome de tratamento que será } \\
\text { utilizado para referenciá-lo na rede. As } \\
\text { opções são: masculino (ele), feminino (ela) } \\
\text { e neutro (ele). Apesar de ser uma opção } \\
\text { diferente, ao escolher " neutro", o Facebook } \\
\text { utiliza o pronome "ele" para referenciar o } \\
\text { usuário. Isso é potencialmente opressor, de } \\
\text { acordo com os dados levantados por Pereira } \\
\text { e Baranauskas (2015), já que o usuário que } \\
\text { seleciona a opção "neutro" não deseja ser } \\
\text { referenciado pelo pronome masculino. }\end{array}$ & OcOp 3 \\
\hline R004 & $\begin{array}{l}\text { Publicações } \\
\text { ofensivas são } \\
\text { fáceis de ser } \\
\text { compartilhadas. }\end{array}$ & $\begin{array}{l}\text { PAf1, PAf4 e } \\
\text { PAf5. }\end{array}$ & $\begin{array}{l}\text { O conteúdo de uma publicação só é avaliado } \\
\text { pelo Facebook após a denúncia de usuários. } \\
\text { Segundo os dados apresentados por Pereira } \\
\text { e Baranauskas } \\
\text { moderação em relação esse tipo de } \\
\text { ao conteúdo }\end{array}$ & OcOp 4, OcOp 5 \\
\hline
\end{tabular}




\begin{tabular}{|c|c|c|c|c|}
\hline & & & $\begin{array}{l}\text { compartilhado (i.e., baseado apenas em } \\
\text { denúncias) pode favorecer } \\
\text { compartilhamento de publicações ofensivas } \\
\text { e opressoras, que, mesmo denunciadas, até } \\
\text { serem investigadas, podem disseminar } \\
\text { rapidamente na rede. }\end{array}$ & \\
\hline R005 & $\begin{array}{l}\text { Configurações } \\
\text { iniciais de } \\
\text { privacidade } \\
\text { permitem } \\
\text { interações } \\
\text { indesejadas. }\end{array}$ & $\begin{array}{l}\text { PAf1, PAf4 e } \\
\text { PAf5. }\end{array}$ & $\begin{array}{l}\text { Logo após a criação da conta, as } \\
\text { configurações de privacidade definidas pelo } \\
\text { Facebook para o usuário permitem que } \\
\text { qualquer pessoa cadastrada na rede entre em } \\
\text { contato com o dono do perfil (e.g., } \\
\text { mensagem via chat). Dessa maneira, podem } \\
\text { ocorrer interações indesejadas, como o } \\
\text { recebimento de mensagens de cunho } \\
\text { ofensivo, o que é considerado um caso de } \\
\text { opressão, como apresentado por Pereira e } \\
\text { Baranauskas (2015) }\end{array}$ & OcOp 5, OcOp 6 \\
\hline R006 & $\begin{array}{lr}\text { Falta } & \text { de } \\
\text { verificação } & \text { para } \\
\text { criar perfis. } & \end{array}$ & PAf4, PAf 5 & $\begin{array}{l}\text { Quando um usuário deseja criar uma nova } \\
\text { conta no Facebook, é possível utilizá-la } \\
\text { mesmo sem confirmar e-mail. Segundo os } \\
\text { dados apresentados por Pereira e } \\
\text { Baranauskas (2015), isso pode facilitar a } \\
\text { criação de contas falsas, por exemplo, para } \\
\text { assediar outros usuários. }\end{array}$ & OcOp 6 \\
\hline
\end{tabular}
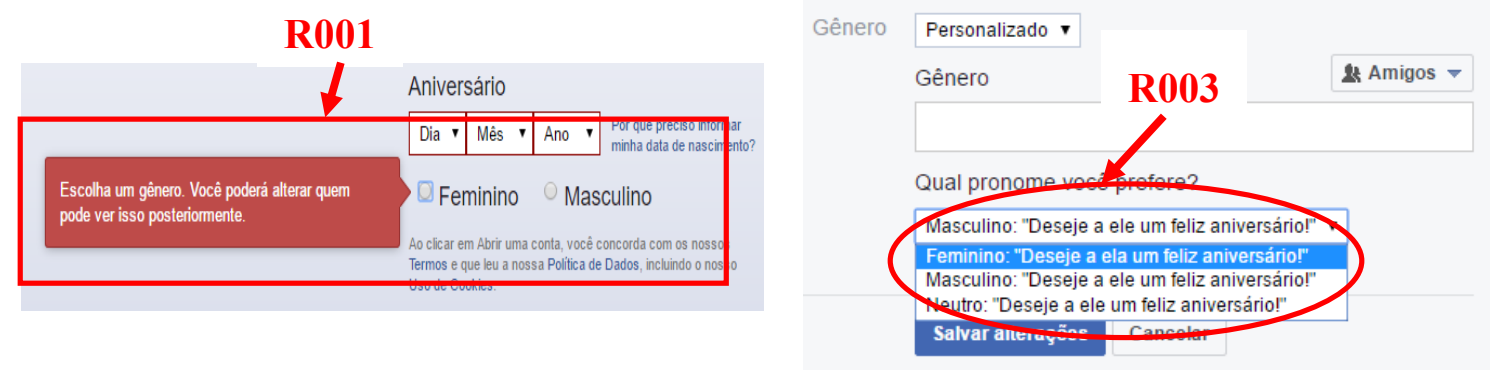

Figura 2. Exemplos de Rupturas na Afetibilidade que refletem em Opressão

A partir dos dados apresentados é possível observar que a inspeção no Facebook, por meio do MIS, permitiu identificar não apenas as estratégias de afetibilidade adotadas no modelo de interface e interação desse sistema, mas também a existência de rupturas, observadas a partir da violação de princípios de afetibilidade, que podem refletir em potenciais casos de opressão contra o público LGBT, como apresentado na Tabela 5.

Dessa maneira, os resultados levantados sustentam o argumento de que a análise da interface de redes sociais online, sob a perspectiva dos princípios de afetibilidade, auxilia na avaliação da opressão de gênero em interfaces. Uma vez que as violações desses princípios podem refletir em baixa afetibilidade e isso pode ter como consequência a ocorrência de opressão sobre o usuário [Pereira e Baranauskas, 2015][Hayashi et al. 2015].

\section{Opressão de Gênero no Facebook percebida por Usuários LGBTs}

Com o objetivo de investigar como os usuários LGBTs percebem a opressão na interface do Facebook, a última etapa dessa pesquisa consistiu na aplicação de um questionário online que permitiu caracterizar: (1) o perfil do usuário LGBT e as (2) ocorrências de opressão gênero já percebidas e/ou vivenciadas por eles. 
O questionário foi aplicado no período de 13 à 19 de setembro de 2016 e sua divulgação foi realizada por meio de redes sociais e e-mails. Foram priorizados grupos de usuários voltados para pessoas LGBTs. Participaram dessa pesquisa 157 usuários LGBTs, com idade entre 18 e 35 anos, que utilizam o Facebook pelo menos 5 vezes por semana.

Inicialmente, os usuários foram questionados se já sofreram ou presenciaram algum caso de opressão no Facebook. A maioria (98\%), respondeu que sim. De forma complementar, os participantes foram questionados em relação à quais casos de opressão sofreram ou presenciaram nessa rede social online. Os casos relatados referemse às possíveis ocorrências de opressão identificadas a partir das rupturas de afetibilidade no modelo de interface e interação do sistema (listadas na Tabela 5).

Para cada ocorrência, o usuário deveria indicar, em uma escala de 1 a 4 , o quanto ela contribuía para o sentimento de opressão durante o uso do Facebook. Essa questão não era obrigatória e, além disso, o participante poderia indicar outros casos de opressão vivenciados ou ainda marcar a opção "Nenhuma ocorrência", indicando que não observou situações opressoras no Facebook. O gráfico da Figura 3 sumariza os resultados obtidos.

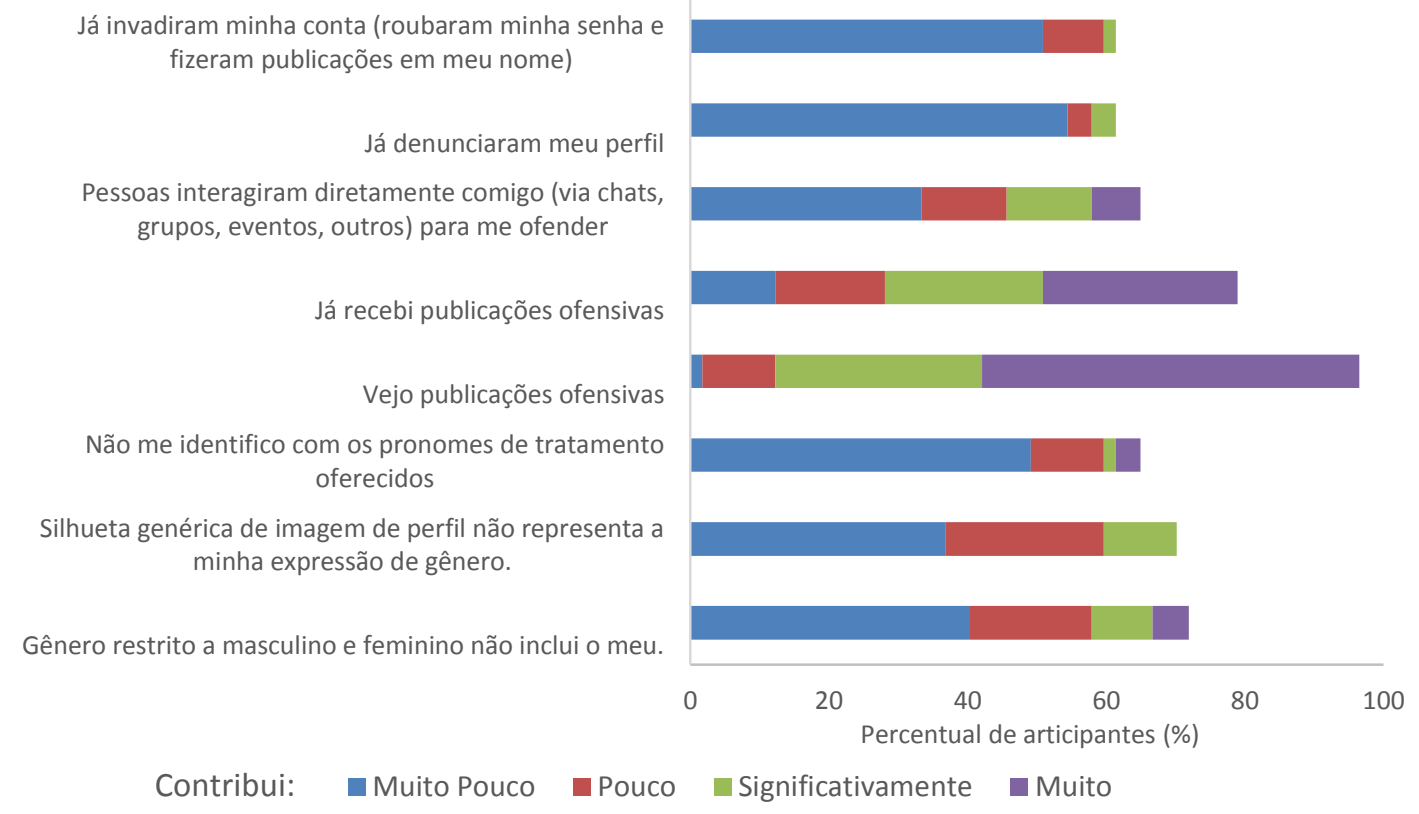

Figura 3. Fatores que contribuem ou contribuíram para a opressão

Por meio da Figura 3 é possível observar que a maioria (90\%) declara que publicações ofensivas, sejam elas direcionadas ao próprio usuário ou não, contribuem significativamente ou contribuem muito para o sentimento de opressão. Além disso, pelo menos $61 \%$, indicaram ter vivenciado ou presenciado as outras situações opressoras listadas, afirmando que elas contribuem para o sentimento de opressão no Facebook, mesmo que muito pouco.

Sendo assim, é possível constatar que, de fato as violações (i.e., rupturas) dos princípios de afetibilidade refletiram em ocorrências de opressão de gênero que já foram vivenciadas pelos usuários LGBTs participantes dessa pesquisa. Evidencia-se então a importância de endereçar aspectos de afetibilidade na interface das redes sociais, e, além 
disso, comunicar de forma clara a existência dessas estratégias de modo que os usuários possam de fato percebê-las, evitando assim que ocorram rupturas de comunicação que levam a opressão de gênero.

\section{Discussão dos Resultados}

A aplicação do MIS permitiu identificar que o projetista do Facebook endereça aspectos de afetibilidade na interface do sistema. Porém, apesar desse endereçamento no modelo de interface e interação dessa rede social, existem rupturas de comunicação relacionadas à afetibilidade que podem refletir em casos de opressão para o público LGBT. Dessa maneira, é possível argumentar que a análise da interface desse tipo de sistema, sob a perspectiva de afetibilidade, pode auxiliar na avaliação de aspectos relacionados à opressão de gênero.

A pesquisa realizada com os usuários LGBTs reforça esse argumento, uma vez que foi demonstrado que os possíveis casos de opressão, vinculados às violações dos princípios de afetibilidade, já foram vivenciados ou observados por esses usuários durante a utilização do Facebook.

Sendo assim, esse trabalho sustenta o argumento de que a partir da violação dos princípios de afetibilidade é possível caracterizar situações opressoras que podem ser vivenciadas por usuários LGBTs. Isso é relevante porque, conforme argumentado por Pereira e Baranauskas (2015), no projeto e avaliação de sistemas colaborativos, é importante fazer uso de recursos que permitam refletir sobre possíveis ocorrências de opressão de gênero, de modo que quando identificadas, elas possam ser contornadas visando uma melhor experiência dos usuários independente do seu gênero e/ou orientação sexual [Pereira e Baranauskas, 2015].

\section{Conclusões e Trabalhos Futuros}

Neste trabalho, foi apresentada uma discussão da aplicabilidade dos princípios de afetibilidade para caracterizar opressão de gênero contra usuários LGBTs no modelo de interface e interação de redes sociais online. Para isso, foi realizado um estudo de caso no Facebook e os resultados demonstraram que, apesar do projetista do Facebook adotar as estratégias de afetibilidade, ainda existem rupturas no modelo de interface e interação que podem refletir em casos de opressão contra usuários LGBT. Logo, uma avaliação guiada pelos princípios de afetibilidade pode auxiliar na caracterização de situações potencialmente opressoras para esse grupo de usuários.

Dessa forma, no âmbito de contribuições, este estudo reforça a importância do endereçamento dos princípios de afetibilidade em redes sociais online, contribuindo com a consolidação desses princípios como estratégias para aprimorar a experiência satisfatória do usuário. De maneira complementar, reforça o argumento de que os princípios de afetibilidade, se violados, podem refletir em opressão de gênero. Portanto, a análise de sistemas sob a perspectiva desses princípios pode auxiliar na identificação de potenciais casos de opressão de gênero.

Em termos teóricos, os resultados da aplicação do MIS contribuem para a consolidação desse método na identificação de estratégias de qualidades de uso em sistemas colaborativos. Finalmente, a metodologia adotada para a condução desse trabalho pode ser explorada por outros pesquisadores para avaliar tanto afetibilidade quanto opressão em redes sociais. 
Como trabalhos futuros, um ponto a ser investigado é a possibilidade de criação de uma metodologia que permita identificar signos na interface que possam indicar possíveis casos de opressão, de modo que seja possível contorná-los ainda em tempo de projeto. Isso auxiliaria no projeto e avaliação de sistemas que buscam a motivação de usuários e sua utilização contínua. Além disso, seria interessante explorar como estratégias e rupturas de afetibilidade podem refletir em opressão contra outros grupos de usuário (e.g., mulheres e pessoas com deficiência).

\section{Referëncias}

Barbosa, G. A. R.; Gantos, G. E. e Pereira, V. Caracterização qualitativa da sociabilidade no Facebook. In: Proc. of IHC. 2013. p. 72-81.

Boehner, K.; Paula, R.; Dourish, P. e Sengers, P. How Emotion is Made and Measured. International Journal of Human-Computer Studies, Academic Press, Inc., Duluth, MN, USA, v. 25, n. 4, p. 275-291, 2007.

Butler, J. Gender Trouble: Feminism and the Subversion of Identity. Routledge, 1999.

de Souza, C. S., Leitão, C. F., Prates, R. O., and da Silva, E. J. 2006. The semiotic inspection method. In: Proc. of IHC'06, p. 148-157.

Duggan, M., Ellison, N. B., Lampe, C., Lenhart, A. and Mary Madden, M. 2015. Social Media Update 2014. In Pew Internet and American Life Project. Available in: < https://goo.gl/LOPiH3>, Acesso: Mar - 18, 2017.

Duggan, M., and Page, D. 2015. Mobile Messaging and Social Media 2015. In Pew Research Center. Available in: < https://goo.gl/LOPiH3>, Acesso: Mar - 18, 2017.

Hayashi, E. C. S.; Posada, J. E. G.; Baranauskas e M. C. C. Explorando princípios de Afetibilidade no redesign de aplicações para contextos educacionais. In: Proc. of SBIE. 2013. p. 788-797.

Hayashi, E. C. S.; Posada, J. E. G.; Pereira, R. e Baranauskas, M. C. C. Exploring Principles for Affectibility in the Design of Mobile Applications. In: Proc. of IHC. 2015. p. 83-92. 25

Kannabiran, G. e Petersen, M. G. Politics at the interface: A Foucaldian analysis. In: Proc. of NordiCHI 2010. p. 695-698.

Killermann, S. Breaking through the binary: Gender explained using continuums. 2011. Disponível em: <https://goo.gl/zqW4Yk>. Acesso: Mar - 18, 2017.

Pereira, G. C. e Baranauskas, M. C. C. Opressões de identidade de gênero e orientação sexual percebidas em interfaces de usuário de sistemas digitais: um estudo exploratório. In: Proc of. IHC. 2015. p. 93-102.

Reis, S. de S. and Prates, R. O. 2011. Applicability of the Semiotic Inspection Method: a Systematic Literature Review. In: Proc. of X IHC \& V CLIHC'11, p. 177-186.

Tomagnini, L.; Barbosa, G. A. R.; Santos, G. E. e Silva, I. S. 2016. Caracterização das Estratégias de Qualidade de Uso que Potencializam a Utilização Contínua de Aplicativos Colaborativos de Navegação: Um estudo de caso no Waze In Proc. of SBSC 2016. 